\title{
Aprendiendo a mirar A TRAVÉS DE NUESTRO PAISAJE COTIDIANO
}

Aprendiendo a mirar . Learning to Look. Apprendendo a guardare
. Learning to Look. Apprendendo a guardare. Aprendiendo a mirar . Learning
to Look. Aprendiendo a mirar . Learning to Look. Apprendendo
a guardare. Learning to Look. Apprendendo a guardare. Aprendiendo a
mirar. Learning to Look. Aprendiendo a mirar . Learning to Look .
Apprendendo a guardare . Learning to Look. Apprendendo a guardare .
Aprendiendo a mirar . Learning to Look. Aprendiendo a mirar. Learning to
Look. Apprendendo a guardare. Learning to Look. Apprendendo a guardare
Aprendiendo a mirar . Learning to Look. Aprendiendo a mirar. Learning
to Look. Apprendendo a guardare . Learning to Look. Apprendendo
a guardare. Aprendiendo a mirar . Learning to Look . Aprendiendo a
mirar. Learning to Look. Apprendendo a guardare. Learning to
Look. Apprendendo a guardare. Aprendiendo a mirar . Learning to Look .
Aprendiendo a mirar. Learning to Look. Apprendendo a guardare


Aprendiendo a mirar A TRAVÉS DE NUESTRO PAISAJE COTIDIANO

LEARNING TO LOOK

Through EVERYDAY LANDSCAPE

Apprendendo a guardare

ATTRAVERSO IL PAESAggio QUOTIDIANO 


\section{APRENDiENdo a mirar}

A TRAVÉS DE NUESTRO PAISAJE COTIDIANO

\section{Bibliografía . Bibliography . Bibliografia}

Howard, P.J. (2011): An introduction to landscape. Ashgate.

Lickwar, P. y Crawford, K. (2014): Looking up, Looking down. Journal of Landscape Architecture, Vol. 9,

issue 3. 2014, pp. 66-71.

Richardson, L. (2010): Seeing Empty Space. European Journal of Philosophy, 18:2. (DOI: 10.1111/ j.1468-0378. 2008.00341.x)

Spirn, A. W. (2013): The language of Landscape: Literacy, Identity, Poetry, and Power. Urban NS05, pp. 17-34.

Tuan, Y. (1990): Topophilia. A study of Environmental Perceptions, Attitudes, and Values. Columbia University Press, 260 págs.
Nuestra comprensión del paisaje muestra la manera en que interpretamos la realidad, es decir, la manera en que percibimos aquello que nos rodea. Un primer paso en el aprendizaje de los conceptos relacionados, bien con el análisis, bien con el proyecto de paisaje, es poner nuestros sentidos a trabajar de manera proactiva, tomando conciencia de los sentimientos y actitudes que en nosotros despierta, en este caso, la configuración espacial de los lugares que recorremos.

Inauguramos el curso de Urbanismo 4, semestre monográfico dedicado al Paisaje Urbano y Territorial, con una práctica encaminada a despertar los sentidos, poniéndolos al servicio de una nueva mirada hacia la realidad cotidiana, con una doble finalidad: analítica y proyectual.

Esta publicación recoge una breve muestra de las aproximaciones inéditas, realizadas por estudiantes de cuarto año del Grado en Arquitectura y Grado en Fundamentos de la Arquitectura de la Universidad de Alicante. Se trata, por tanto, de una experiencia docente cuya difusión tiene el objetivo de servir de experiencia a cualquier estudiante, docente o investigador inmerso en esta temática. 
La preeminencia de la vista, sobre el resto de los sentidos, en la interpretación del paisaje, se puede incluso inferir de la manera en que la percepción está expresada en el texto del Convenio Europeo del Paisaje. Tal como señala Peter Howard, a lo largo de la historia el concepto de paisaje se ha vinculado a las artes visuales, el paisaje natural y el cultural se han comprendido sobre todo a partir de lo que se ve (Howard, 2011:79). Esta apreciación contrasta con el punto de vista de Yi-Fu Tuan, para el que el mundo percibido a través de la mirada es más abstracto que a través de otros sentidos (Tuan, 1990:10), donde la vista incorpora mucha información que el subconsciente procesa, y que, junto con el resto de sentidos, genera la experiencia vivida.

Los límites de lo percibido están en nuestra propia limitación sensorial (Richardson, 2010:234); más allá de los límites físicos espaciales desde el punto de vista visual, está la experiencia del lugar conectada con una comprensión multisensorial y cultural. En definitiva, es una forma de lenguaje, con todas las características propias, equivalentes a la estructura, formación y función que encontramos en las palabras y en las partes de un discurso (Spirn, 2013).

La fotografía puede entenderse como un filtro entre el mundo exterior y las propias imágenes mentales (Spirn, 2013). Son expresión y comunicación de la interpretación personal de quien, primero toma las imágenes y luego las selecciona. Inspirado en el trabajo llevado a cabo por Phoebe Lickwar y Katya Crawford: "Looking up, Looking down" (Lickwar \& Crawford, 2014), la actividad planteada focaliza la experiencia perceptiva del paisaje en la mirada. Lickwar y Crawford combinan dos métodos visuales para aprender sobre el lugar a través de la observación: mirar hacia arriba, hacia el cielo; y mirar hacia abajo, buscando los detalles de la superficie que recorremos. Para la observación en cada dirección, las autoras utilizan una técnica fotográfica específica, con el fin de captar la esencia del lugar o recomponer la superficie que se ha recorrido.

La práctica realizada toma algunos de los condicionantes propuestos en el trabajo de Lickwar y Crawford, incluyendo la composición de las imágenes; pero, adapta los objetivos docentes concretos a la estrategia de aprendizaje diseñada para los estudiantes de arquitectura, que son los siguientes:

A. Despertar los sentidos como herramientas necesarias para abordar la aproximación al paisaje y sus especificidades.

B. Evidenciar, a través deesta práctica, la preeminencia de la vista, frente al resto de los sentidos, para así reivindicarlos como instrumentos de interpretación de la experiencia vivida.

C. Mostrar cómo la fotografía, medio visual, y el texto, medio escrito, utilizan mecanismos diferentes de descripción, apelando a sentidos distintos. La descripción de un paisaje a través del texto escrito se apoya en los sonidos, el olfato y los sentimientos que genera el lugar; mientras que la fotografía muda apela a nuestra agudeza visual. 


\section{Proceso...}

1. Leer el artículo "Looking up, Looking down" de Phoebe Lickwar y Katya Crawford (2014). Esta lectura muestra, más que el método, la esencia de este ejercicio práctico.

2. Elegir un entorno cotidiano que sea referencia vital para el estudiante, cualquier contexto que no tenga carácter excepcional:

- Mi camino a... un lugar frecuentado y habitual: lugar de estudio, deporte, trabajo, ocio, paseo de la mascota...

- En el umbral de mi casa...a la hora de salida o llegada habitual...(estático/en movimiento)

- Desde mi ventana, mi terraza... donde estudio, veo la tele o leo (estático)

3. Fotografiar: Aproximarse al lugar elegido con los sentidos puestos en la tarea a abordar. Para la toma de las fotografías, la línea del horizonte es el límite para trabajar la mirada "hacia arriba" y "hacia abajo", utilizando preferiblemente la cámara del teléfono móvil.

4. Recopilar las coordenadas geográficas que sitúen exactamente la posición del lugar escogido.
5. Elaborar un díptico:

- Composición visual, elaborada a partir de las fotografías, siguiendo la idea del patrón compositivo del trabajo de Lickwar y Crawford.

- Texto descriptivo de la experiencia del lugar. Este texto no debe ser una descripción de las imágenes tomadas, sino una manera de contar el paisaje percibido.

\section{Resultados...}

Los siguientes dípticos son una muestra representativa de muchos más. Los textos y las imágenes son las que originalmente entregaron los autores de cada ejercicio, sin correcciones.

El estilo de los textos requiere más entrenamiento, pero ha sido éste el punto de partida necesario para poder avanzar.

La práctica, encaminada a despertar los sentidos para convertirlos en herramientas de trabajo, así como, a entender la diferencia entre fotografiar un paisaje y escribir sobre el mismo, ha resultado un buen primer paso. 


\section{LEARNING TO LOOK Through Everyday LANDSCAPE}

The way we understand landscape shows how we interpret reality and perceive everything around us. The first step in learning about concepts related to both landscape study and planning is to be proactive about how we use our senses. This means becoming aware of the feelings and attitudes awakened by the spatial configuration of the places we frequent.

Our introduction to Landscape Urbanism begins with a specific practical activity aimed at awakening the senses, and developing them to provide a renewed viewpoint of everyday reality. The activity has a twofold purpose: analytical and design-based. 
This booklet gathers a brief representative and unedited sample of the different approaches taken by fourth year students in the Degrees of Architecture and Fundamentals of Architecture from the Polytechnic School -University of Alicante, Spain. This is a record of a teaching experience, which will hopefully provide a new reference for students, lecturers or researchers in this field.

The preeminence of sight, over the other senses, in landscapeinterpretation is something thatcan beinferred from the way the European Landscape Convention refers to perception. Furthermore, as Peter Howard points out, throughout history, the landscape concept has been firmly connected with visual arts, wilderness or natural landscape, as well as, cultural landscape, and has been "skewed to what can be seen" (Howard, 2011:79). This contrasts with Yi-Fu Tuan's view that what we perceive through sight is more abstract than what is perceived through other senses, such as smell and hearing.

Despite the visual field being larger than that of the other senses, it does not produce the same intensity of emotional response (Tuan, 1990: 10). Place experience is connected with a multisensory and cultural understanding. It is a form oflanguage, withall the specific characteristics, equivalent to structure, composition and function in word formation or speech parts (Spirn, 2013: 20).

Photography can be understood as a filter between two worlds: exterior and interior mental images (Spirn, 2013: 22), which are an expression and communication of the person who both takes and then selects the photograph. Inspired by Phoebe Lickwar and Katya Crawford's proposal in "Looking up, looking down" (Lickwar \& Crawford, 2014), the practical activity given to students was focused on the visual perceptive experience of landscape. Lickwar and Crawford combine two visual methods to learn about place through observation: looking up, towards the sky; and looking down, seeking details on the ground we tread.

This activity adapts some of the techniques used in Lickwar and Crawford's work, including image composition, but is tailored to the learning objectives of architecture students, which involve:

A. Stimulating senses as necessary tools to approach landscape understanding and its particularities.

B. Highlighting the supremacy of sight but recognizing other senses as important instruments for an holistic perception of the experience.

C. Using photography, as visual media, and text, as written media, suggests that there are different ways of understanding landscape: written text is the vehicle through which sounds, smells and feelings related to the place can be described; the photograph captures a visual image at a specific point in time. 


\section{Process...}

1. Read the article "Looking up, Looking down" from Phoebe Lickwar and Katya Crawford (2014). This reading is more than a method, it is an inspiration which will help you to understand the spirit of this practical activity.

2. Choose a well frequented environment, any context related to your daily routine:

- Your route to university; the sports club; shops, for example ...

- Surrounding areas of your home (static or in motion)

- From your window, balcony, terrace, where you study, read, watch TV, for example. (static)

3. Photograph your chosen place: Approaching it, observing with all your senses. To take the photographs, the starting point is the horizon as the dividing line between up and down. Tilt your head towards the sky to discover what happens when your head is "looking up" and shoot. The frame to discover what is happening near your feet at ground level, is the "looking down" action. A smart phone camera is recommended.

4. Indicate the geographical coordinates of the chosen place.
5. Create a two page brochure on A4 paper which includes the following:

- Visual composition following Lickwar and Crawford's layout idea.

- Text describing your personal experience of the place. This text must not be a simple description of the images but a description of the sensations felt through observations made using all of your senses.

\section{Outcome...}

The following work is a representative selection of text and images reproduced from original students' work. This exercise received positive feedback as a useful introduction to landscape issues. Photographing places and writing about them are complementary tasks which awaken all the senses and show how they become an important work tool for providing a holistic approach to place. 


\section{Apprendendo a guardare ATtraverso il PaESAggio QUOTIDiANo}

La nostra comprensione del paesaggio mostra il modo con il quale interpretiamo la realtà, ovvero la maniera con la quale percepiamo ciò che ci circonda. Il primo passo per appendere i concetti relazionati, sia con l'analisi, sia con il progetto del paesaggio, è quello di abituare i nostri sensi a lavorare in modo proattivo, prendendo atto dei sentimenti e dei comportamenti che in questo caso risveglia in noi la configurazione spaziale dei luoghi che attraversiamo.

Stiamo inaugurando il corso di Urbanistica 4, un semestre monografico dedicato al paesaggio Urbano e Territoriale, con un esercizio che impone di risvegliare i sensi in maniera tale da ottenere un differente sguardo della realtà di tutti i giorni con un duplice scopo: analitico e progettuale.

Questa pubblicazione contiene una breve raccolta di elaborati inediti, realizzati dagli studenti del quarto anno del corso di laurea in Architettura e Fondamenti dell' Architettura dell'Università di Alicante. Si tratta, quindi, di una disciplina, il cui obiettivo è finalizzato a servire come esperienza per ogni studente, docente o ricercatore immerso in questa tematica. 
L'importanza della vista, sugli altri sensi, nell'interpretazione del paesaggio, può anche essere dedotta dal modo in cui la percezione è espressa nel testo della Convenzione Europea del paesaggio. Come sottolinea Peter Howard, nel corso della storia il concetto di paesaggio è stato messo in relazione con arti visive, il paesaggio naturale e culturale è stato dedotto principalmente da quello che si vede (Howard, 2011: 79). Questa posizione è in contrasto con la visione di Yi$\mathrm{Fu}$ Tuan, per il quale il mondo percepito attraverso gli occhi è più astratto che attraverso altri sensi (Tuan, 1990: 10), dove la vista comprende un sacco di informazioni che il subconscio elabora, e, insieme con gli altri sensi, crea l'esperienza.

I limiti di ciò che è percepito sono nelle nostre stesse limitazioni sensoriali (Richardson, 2010: 234); oltre i confini fisici spaziali dal punto di vista visivo, vi è l'esperienza del luogo connessa con una comprensione multi-sensoriale e culturale. In sintesi, è una forma di linguaggio, con tutte le caratteristiche proprie, equivalenti alla struttura, formazione e funzione che riscontriamo nelle parole e nelle parti di un discorso (Spirn, 2013).

La fotografia può essere intesa come un filtro tra il mondo esterno e le proprie immagini mentali (Spirn, 2013). Sono l'espressione e la comunicazione dell' interpretazione personale di ognuno, che prima acquisisce le immagini e poi le seleziona. Ispirato al lavoro svolto da Phoebe Lickwar e Katya Crawford: "Looking up, Looking down" (Lickwar \& Crawford, 2014), l'attività proposta concentra l'esperienza percettiva del paesaggio attraverso ciò che si osserva. Lickwar e Crawford combinano due metodi visivi per conoscere il luogo attraverso l'osservazione: guardare in alto verso il cielo; e guardare in basso, cercando i dettagli della superficie su cui camminiamo. Per una visione globale, gli autori utilizzano una tecnica fotografica specifica, al fine di catturare l'essenza del luogo o di ricomporre la superficie che si è percorsa.

Nella pratica vengono utilizzate alcune tecniche di rappresentazione, proposte nel lavoro di Lickwar e Crawford, come la composizione delle immagini; ma adattando gli obiettivi scientifici concreti alla strategia di apprendimento pensata per gli studenti di architettura, che sono:

\section{A. Risvegliare i sensi come strumenti per affrontare} il paesaggio e le sue caratteristiche.

B. Evidenziare, attraverso questo esercizio, il primato della vista sugli altri sensi, in modo da rivendicarli come strumenti di interpretazione dell'esperienza vissuta.

C. Mostrare come la fotografia, mezzo visivo, e il testo, mezzo scritto, utilizzano diversi meccanismi di descrizione, facendo appello ai diversi sensi. La descrizione di un paesaggio attraverso il testo scritto è basato sui suoni, odori e sensazioni generati dal posto; mentre la muta fotografia si appella al nostro intuito visivo. 


\section{Processo...}

1. Leggere l'articolo "Looking up, Looking down" di Phoebe Lickware Katya Crawford (2014). Questa lettura mostra, piuttosto che il metodo, l'essenza di questo esercizio pratico.

2. Scegliere un ambiente quotidiano che è di riferimento vitale o importante per lo studente, qualsiasi contesto relativo alla vostra routine quotidiana:

- Il mio cammino a ... un luogo di ritrovo abituale: luogo di studio, di sport, di lavoro, di tempo libero....

- Nellatrio di casa mia ... al momento di uscire o rientrare ... (Statico / movimento)

- Dalla mia finestra, dalla mia veranda ... dove studio, guardo la televisione o leggo...(Statico)

3. Fotografare il tuo luogo prescelto: avvicinarsi ad esso, osservandolo con tutti sensi. Per scattare le fotografie, il punto di partenza è lorizzonte come linea di demarcazione per abituare la vista a ciò che cè al di sopra e al di sotto di esso. Inclinare la testa verso il cielo per scoprire cosa succede quando lo sguardo è verso "l'alto" e inclinarla verso il terreno per scoprire cosa succede quando lo sguardo è verso "il basso". Utilizzare preferibilmente la fotocamera dello smart phon.

4. Indicare le coordinate geografiche del luogo scelto.
5. Creare un opuscolo, costituito da due pagine formato A4, che includa quanto segue :

- Una composizione visiva, seguendo lo schema di Lickwar e Crawford.

- Un testo che descriva la vostra esperienza personale del luogo, il quale non deve essere una semplice descrizione delle immagini, ma bensì delle sensazioni scaturite dalle osservazioni fatte, utilizzando tutti i vostri sensi.

\section{Risultati ...}

I seguenti elaborati sono frutto di un ampia selezione. I testi e le immagini sono quelli originariamente presentati da ognuno degli autori, senza correzioni. Lo stile dei testi richiede più conoscenze, ma è questo il punto di partenza necessario per poter avanzare. La pratica, ideata in definitiva per risvegliare i sensi e trasformarli in strumenti, nonché per capire la differenza tra fotografare un paesaggio e scrivere su di esso, è stata un buon primo passo. 
Seguendo l'esempio di Phoebe Lickwar e Katya Crawford, secondo il quale è possibile ottenere una comprensione della natura e del paesaggio, con lo scatto di una foto, attraverso due metodi: Looking Up and Looking Down; ho deciso di applicarlo al luogo dove trascorro molto spesso parte delle mie giornate, cioè la Plaza de los Luceros in Alicante.

Alzando lo sguardo al cielo (Looking Up), contemplo la vista, mi fermo ad ammirare e mi perdo in essa, come sottolineano Lickwar e Crawford: sognando, ruminando, come se io fossi lì con il corpo ma non la mente, ma allo stesso tempo, stranamente ho una comprensione del tempo. Immortalando la vista attraverso lo scatto di una foto, posso scorgere la cima della "Fuente de los Luceros o de los caballos", la quale è sovrastata da un cielo limpido.

Guardando verso il basso (Looking Down), analizzo e osservo la superficie dove cammino, immortalandola con diverse foto. Alcune, mostrano il suolo sterrato, le piastrelle che decorano la piazza o l'acqua della Fuente, altre, la natura che ci circonda, con i suoi mille colori e profumi.

Tra le foto, quattro sono molto significative, due mostrano l'inciviltà della gente, che lasciano i rifiuti nell'ambiente, come se nulla fosse accaduto, deturpandolo, mentre le restanti mostrano il ciclo della vita, attraverso: l'immagine di un fiore, al cui interno vi sono delle formiche, e l'immagine di una foglia secca.
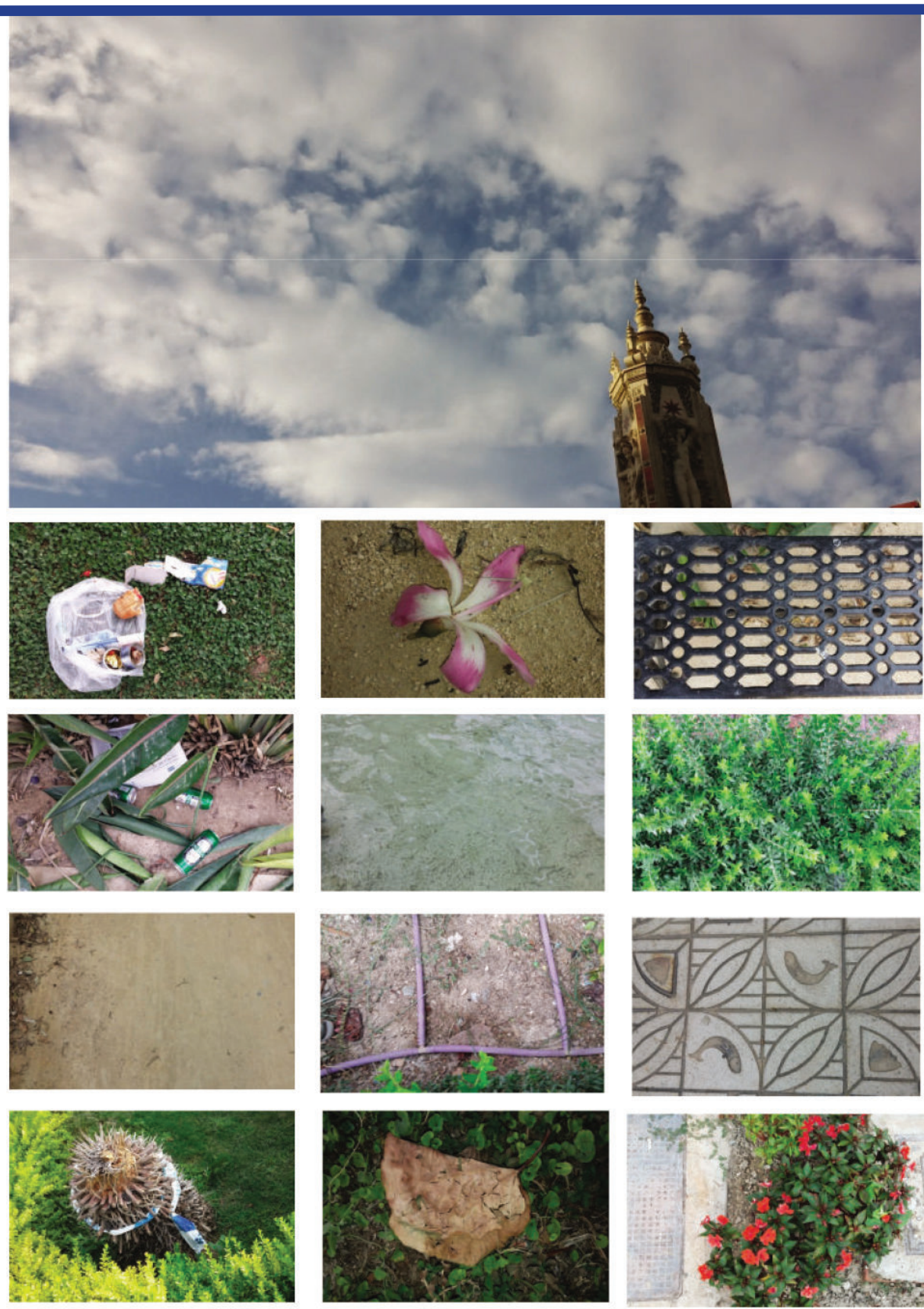
Comienza el camino. Este recorrido, tiene un significado especial para mí, puesto que es uno de esos lugares donde he pasado muchas tardes de mi vida y de mi infancia. Es un lugar con un sentimiento especial, puesto que es aquí donde he crecido, donde he jugado y donde he aprendido. Lo recuerdo con ternura, pero esta vez lo he descubierto de una forma diferente. El trayecto que he fotografiado, se realiza en el interior de un gran parque situado en frente de mi casa. Es un espacio especial, que puedes recorrer con la mirada de un plumazo, o puedes detenerte y descubrir los mil detalles que te muestra. Mirando hacia arriba, he descubierto cientos de miles de cielos, nubes que se mueven y cambian de forma sin darnos a penas cuenta. Con miles de hojas y ramas que se mueven, te tapan o destapan a su antojo. Es un cielo especial con atardeceres y amaneceres diferentes cada día. Yo, en particular, he decidido capturar y guardar una luz intensa, capaz de cegarnos y darnos el calor característico de este paraje, ese calor que me ha acompañado durante tanto tiempo. En la foto, podemos apreciar ese potente sol, inconfundible del septiembre veraniego en Elche.

Mirando hacia abajo, he aprendido a ver $y$ valorar las pequeñas cosas que se confunden con la prisa. Los pequeños detalles que varían dependiendo del día, de la hora y del momento que vayamos a verlos.

Me he acercado a un mundo de colores intensos, de olores e incluso sabores que ya conocía.

Me he encontrado contemplando las diferentes texturas que tiene la naturaleza; el cómo caen las hojas en el suelo; mirando las diferencias entre un pedacito de jardín despoblado y justo al lado repleto de ramas y césped.

Me he sorprendido de los juegos de luz y sombra que da una simple vaya dispuesta en medio del parque; he admirado las pequeñas cosas que han estado siempre, como un candado, y que el tiempo ha desgastado y descolorido.

He percibido el olor a hierba recién mojada, el olor de la tierra, de las flores, y hasta he saboreado el dulce aroma del dátil.

En este paseo he fotografiado cientos de detalles que me han llamado la atención, y de todos ellos he seleccionado unas pocas imágenes, que para mí son las que pueden decir a una persona que no haya estado allí como es ese sitio, e incluso verlo a través de mis ojos y mi experiencia.

Seguramente si volviera a realizar el mismo recorrido volvería a descubrir cosas que no he visto, cosas que han cambiado y cosas nuevas que están en ese lugar.
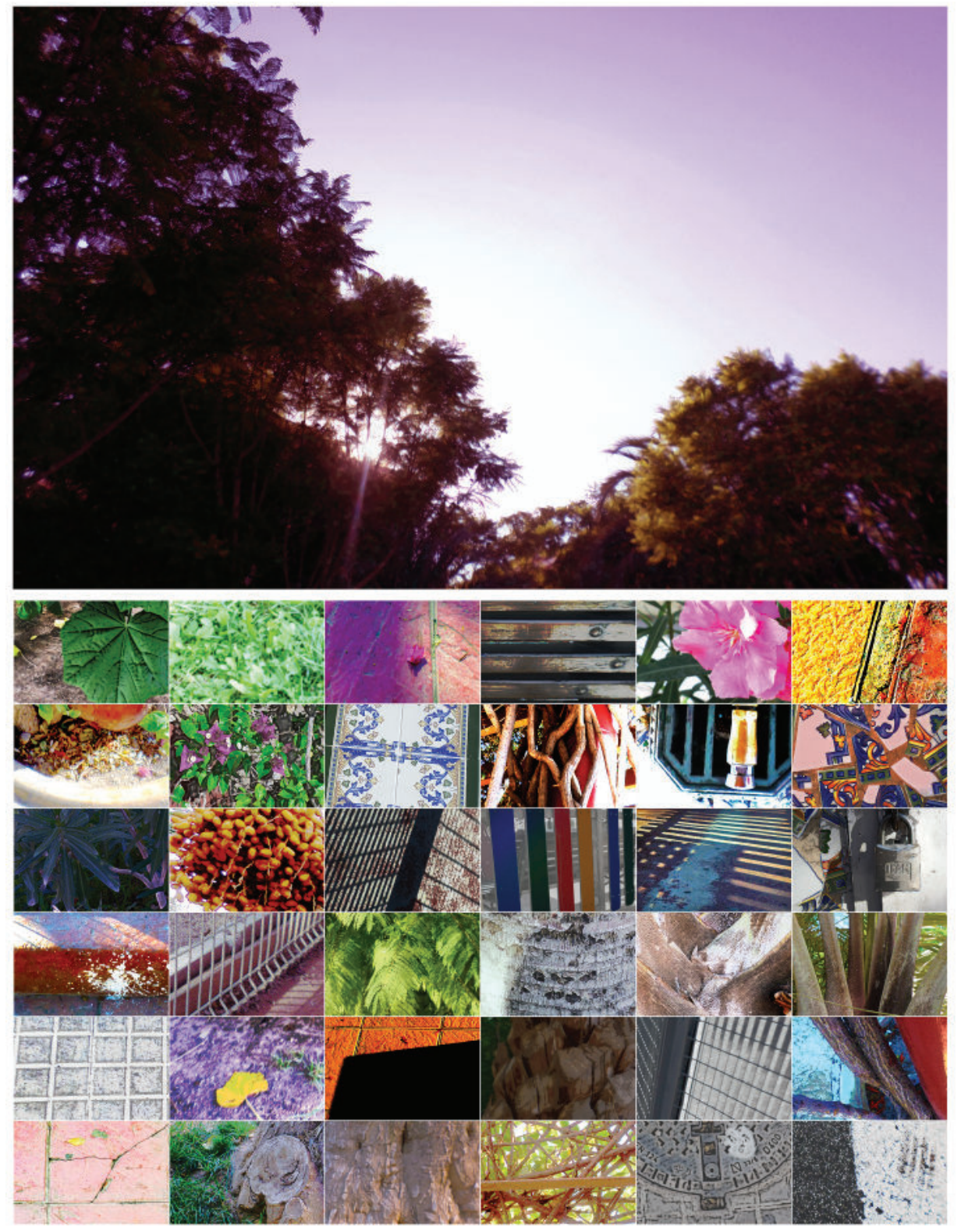
El lugar fotografiado es una de las zonas más céntricas de la ciudad de Castalla. Es un lugar muy transitado y lleno de actividad, tanto económica como cultural por los actos que allí tienen lugar en las fechas señaladas. Es una plaza que ha sido reformada hace ahora sobre cinco años atrás, con algunas modificaciones mas recientemente, y tiene grandes muestras de deterioro en tan poco tiempo. Personalemnte, transito habitualmente esa zona, ya que se situa cerca de mi residencia habitual, no solo como recorrido cotidiano para ir a la universidad sino como paso diario para cualquier otra actividad que desempeñe. No obstante, me resulta difícil recordar cuál era la situación en la que se encontraba antes de la reforma pero lo que sí recuerdo es que se conservaba mucho mejor el paisaje y los medios urbanos que ahora encontramos.

La imagen que se observa con la posición "looking up" es la de una de las mejores vistas que dispone mi pueblo, el Castillo. Además, se observan las luces que muestran las fiestas tradicionales que se han celebrado poco tiempo atrás. La fotografia al estar tomada al medio dia en un periodo estacional veraniego se observa con claridad y el cielo despejado, una imágen nítida redeada de algunas de las edificaciones que ya dan el inicio al casco antiguo de la ciudad. No obstante, este paisaje que se muestra da un recuerdo inmediato a la casa que fue derruida recientemente (sin consentimiento de su propietario, con la consecuente multa administrativa) y que era uno de los símbolos más emblematicos para cualquier ciudadano de la localidad.

Las imágenes de "looking down" hace una muestra muy explicativa de lo que ha sido el cambio en el paisaje urbano como espacio público realmente utilizado (puesto que da cobertura a distintas actividades) y transitado. Las imágenes muestran todo tipo de deterioros en el paisaje desde patologías en los materiales como el impacto social. Este escenario, un tanto desolador, a lo que estaba acostumbrada la población de Castalla muestra como el cambio urbanístico no ha sido del todo exitoso. Lo que pretendia ser una muestra de modernización cambiando pavimento, poniendo luces de recorrido y de estancia, incluso una fuente con cauce de agua continuo, ha resultado ser una presencia abundante de basura, sin agua ni fuente actualmente funcionando, manchas de todo tipo de fluidos y falta de cuidado y ejecución.

Mi interpretación de las fotografías, sobretodo de lo que he elegido fotografiar, está íntimamente sujeto a mi experiencia y cómo he vivido ese cambio en un lugar donde tengo recuerdos desde mi infancia. No obstante, esta visión del paisaje muestra como la oposición de un paisaje emblemático que podría mostrar lo más puro de mi pueblo con el descontento generalizado de que, a pesar de ser un espacio público de éxito, el recorrido que pisamos no compañe esta idea.
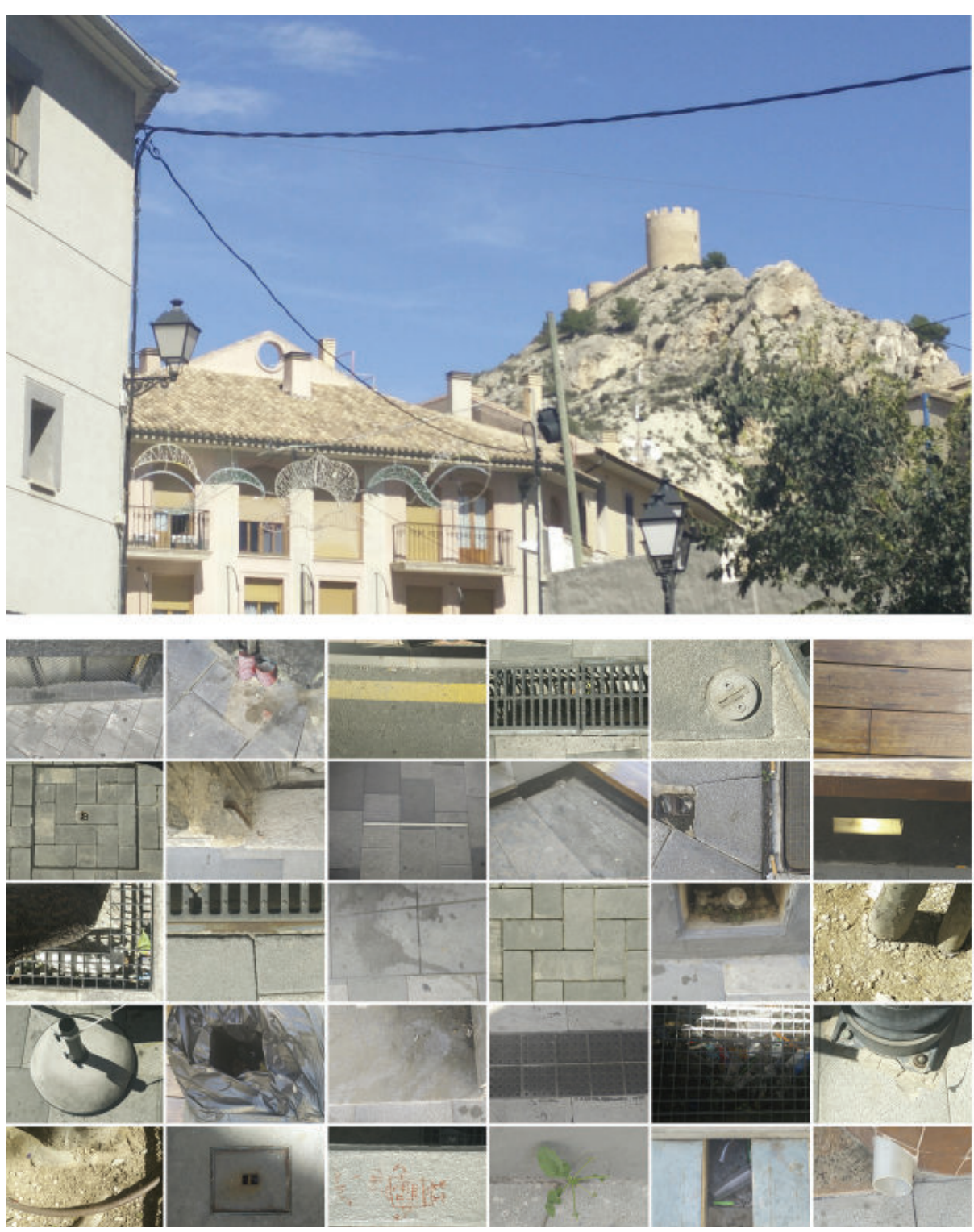
$08.01 \mathrm{am}$. Un Domingo cualquiera. Acabo de levantarme, y antes de tomar el primer café voy a salir a correr, y disfrutar de uno de los últimos días de verano. Es un recorrido de $3 \mathrm{~km}$. por el paseo marítimo de Torrevieja, que cita diariamente a un elevado numero de amantes del deporte callejero. El cariñoso abrazo de la briza marina, y las caricias del sol recién levantado convierten el paseo en algo extraordinariamente agradable a esta hora de la mañana. Se reúne gente de todas las edades, y nunca falta ni competencia, ni motivación. Y entre buscar tu carril, y esquivar la gente que encuentras por el camino, uno nunca se fija en los miles de detalles de la calzada. No sabes cuantos distintos tipos de pavimento vas a pisar hasta llegar a la meta. Ni tampoco cuantas arquetas vas a saltar....

Empiezas a fijarte, y descubres la contrastante mezcla de naturaleza y urbanismo. Uno incorporado en el otro. A veces casi sin claros limites. Las formas orgánicas de la orilla, bordeadas de pura geometría. El indescriptible y aleatorio movimiento de las olas, chocando contra un muro de hormigón gris, perfectamente recto, liso y uniforme.

De repente el muro desaparece. Aparecen las curvas de una playa en la que lo único que queda de la naturaleza es la propia orilla. A continuación el paseo sigue bordeado de un rompeolas aparentemente desordenado, pero con formas geométricas de protagonista.

$\mathrm{Y}$ mientras intentas descubrir el verdadero origen de la calzada, te das cuenta que los objetos que la cubren quieren comunicarse contigo. Anuncian su propietario, o mandan una dedicatoria de agradecimiento a alguien.. Dibujan formas o todo un conjunto de elementos. Marcan los espacios y los hacen resaltar.. Juegan con el orden y el desorden. Marcan un ritmo o lo rompen. O simplemente te ayudan llegar a tu destino.
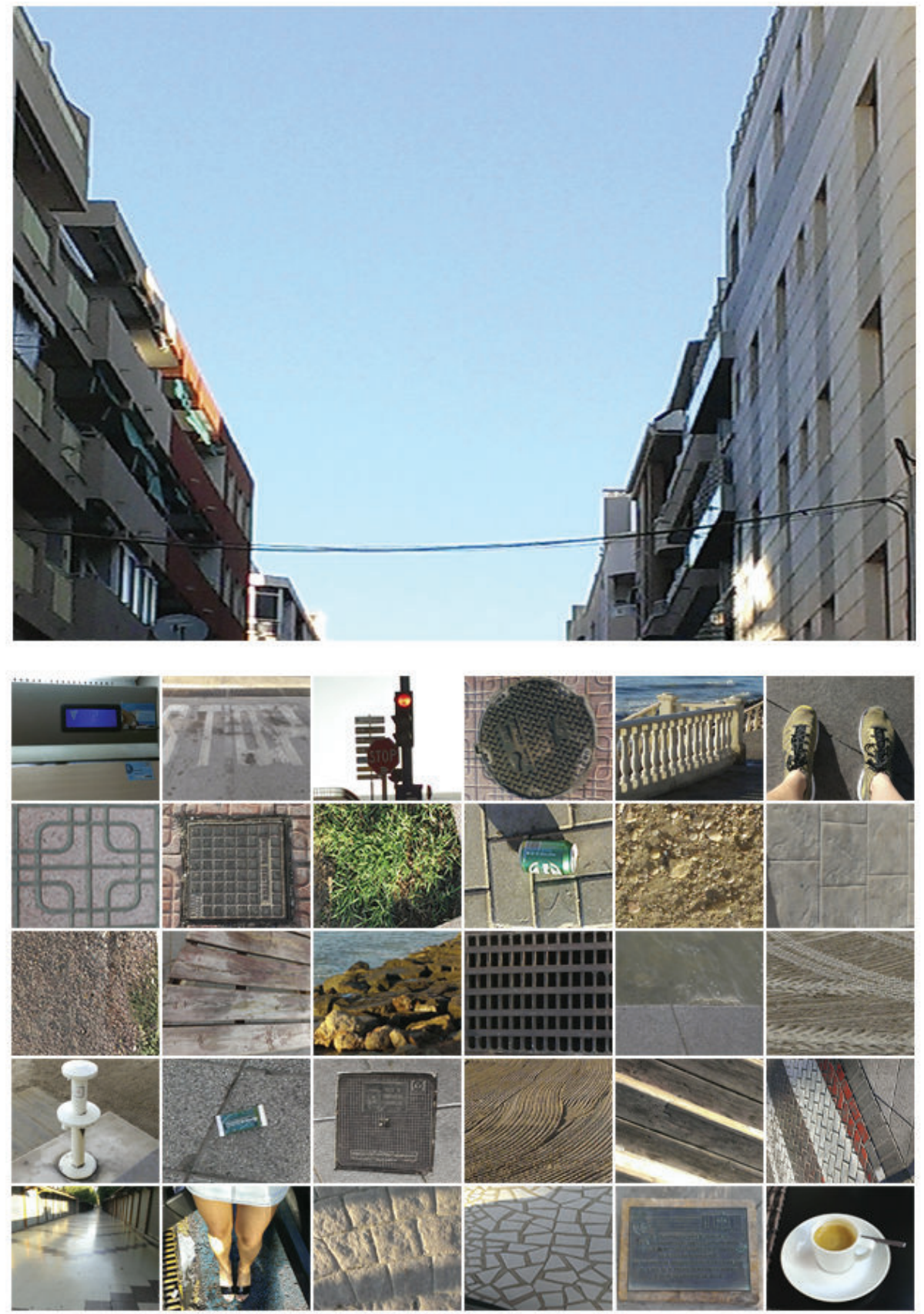

Torrevieja, Spain - 3758'34.4”N 041'00.3”W 
El lugar escogido para la toma de datos es el acceso al edificio donde resido, situado en el barrio de San Blas, y el tramo de acera que hay inmediatamente delante. Es un espacio que transito diariamente siempre que salgo o vuelvo a casa pero, a pesar de ello, siempre que lo recorro tiendo a mirar al frente sin detenerme a observar lo que hay por el suelo alrededor mío, ni tampoco el cielo excepto si quiero saber que tiempo hace en ese momento.

Con esta práctica he podido aprender a mirar más allá de lo cotidiano y fijarme en aquellos detalles que normalmente pasan inadvertidos, no solo para mí sino también probablemente para el resto de personas que día tras día pasan por esta zona al igual que lo hago yo.

En primer lugar, mirando hacia arriba (looking up) se puede observar directamente el cielo, sin más obstáculos que el arbolado plantado, gracias al ancho de la avenida y a que no hay edificación delante. Te puedes fijar en la copa, en las ramas o en como el solo se deja ver entre ellas. La primera fotografía tomada da una gran sensación de infinidad, debido a la uniformidad del color del cielo, sin nubes, tan lejano, en contraste con el árbol que aparece en primer plano.

En segundo lugar, mirando hacia abajo (looking down), y como he comentado anteriormente, aparecen detalles que normalmente uno no se detiene a observar. Son marcas que ponen de manifiesto que el espacio donde se han realizado las fotografías es un espacio público, transitado y en definitiva, vivido. Algunos de estos detalles son fruto de algo natural, como las hojas de los árboles caídas o la pequeña planta que brota entre las juntas del pavimentado, mientras que otros son consecuencia de la acción del hombre como las marcas de pintura, los chicles pegados o el graffitti del bordillo. Algunos son efímeros y han estado poco tiempo como la colilla, la botella o el panfleto y otros son resultado de una acción constante como las marcas de neumáticos o las grietas, sin olvidar los elementos que han estado desde que nació la calle como los diferentes pavimentos, los alcorques, los imbornales o las arquetas de las instalaciones o los desagües.

Esas pequeñas "marcas" que normalmente carecen de importancia son la seña de identidad de esta zona, las que hacen que sea única porque en ninguna otra calle del mundo va a ver la misma mancha o la misma hoja en la misma posición o con la misma forma como están esas ahí.

Considero que esta es una de las grandes ventajas que tiene este estudio, poder darte la oportunidad de acercarte a fotografiar aquellas cosas que jamás antes de habrías parado a observar con más detenimiento (de ahí que haya decidido llamar a esta investigación ZOOM IT). Detalles que ves cada día y que lo más seguro es que no tengan ningún valor para ti, pero que sin embargo dicen mucho de la calle y de lo que pasa en ella, lo cual nos lleva a la conclusión de que quizás para analizar un espacio a gran escala, primero hay que empezar a estudiar los elementos más pequeños del mismo, que son los que otorgan el carácter y aportan información relevante sobre como funciona y lo que pasa en él.
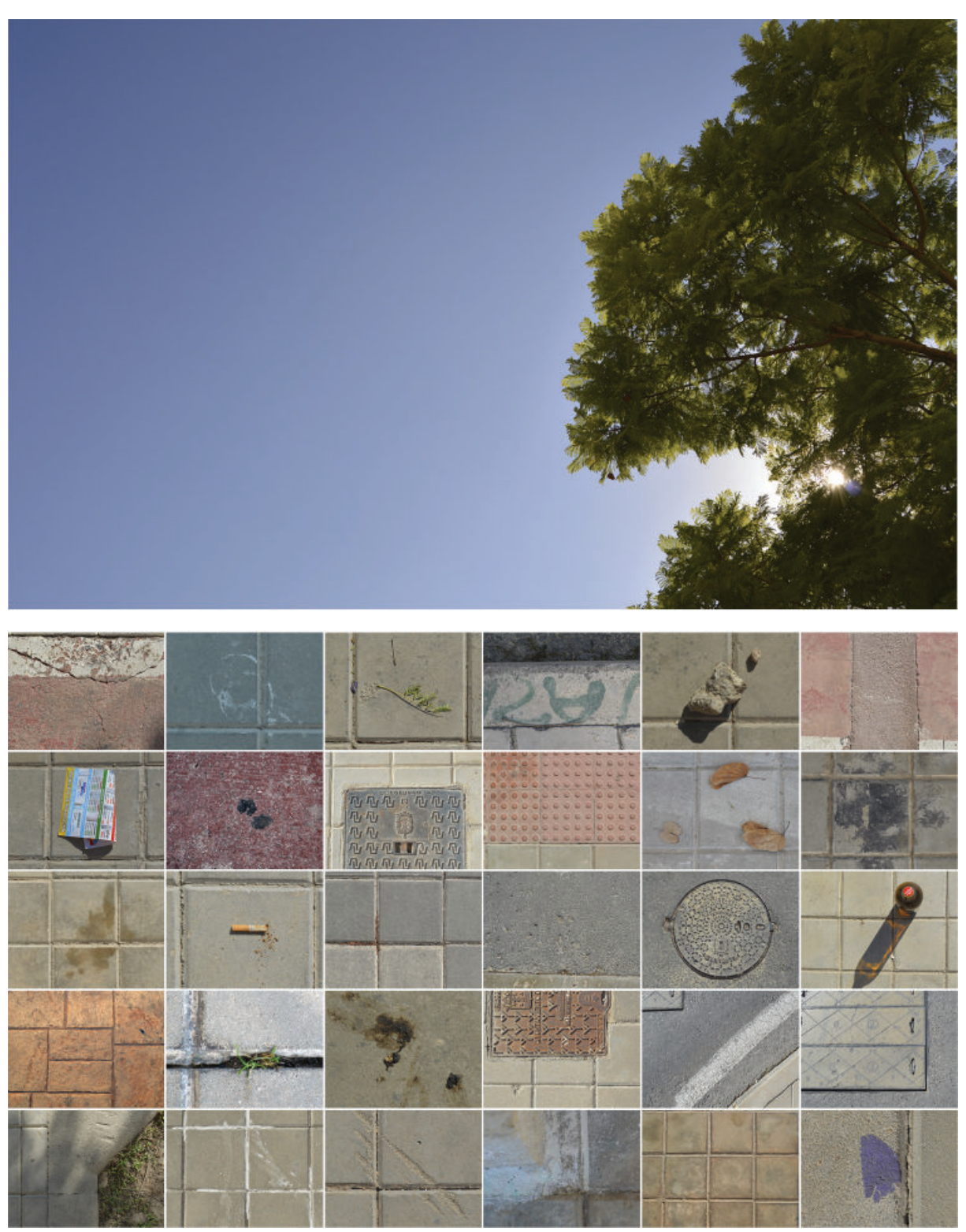
La perfección humana contra el tiempo, Torrellano Rodrigo Martinez Rocamora

Para realizar esta aproximación al paisaje a través de la fotografía he tomado una parte de mi recorrido habitual por los alrededores de mi casa. Las calles donde he desarrollado la práctica en cuestión están delimitadas por variedad de tipologías arquitectónicas y usos diferentes, como edificios de pocas plantas relativamente nuevos, pequeños huertos, un garaje, una antigua fábrica y el polideportivo. Esto le confiere a ese pequeño paisaje una interesante característica, y es que se puede apreciar la lucha existente entre la pulcritud de la obra nueva y el desgaste del tiempo.

En esa mirada detallada durante el corto recorrido observamos los efectos de la naturaleza y la vida de la sociedad en esos inicialmente calculados materiales. El desdibujado de las lineas, la falta azarosa de pintura, la destrucción de las aristas a $90^{\circ}$, el óxido que engulle el hierro, la orina encharcada, el grafiti sobre la pared... Y es ahí donde se hace patente la presencia del tiempo, el tiempo como un destino al que toda la construcción humana está decidido a llegar desde el primer momento en que existe.

Y el paisaje urbano al fin y al cabo es, a mayor escala, un conglomerado de capas superpuestas en el tiempo, pero que es en realidad lo que define el mismo.
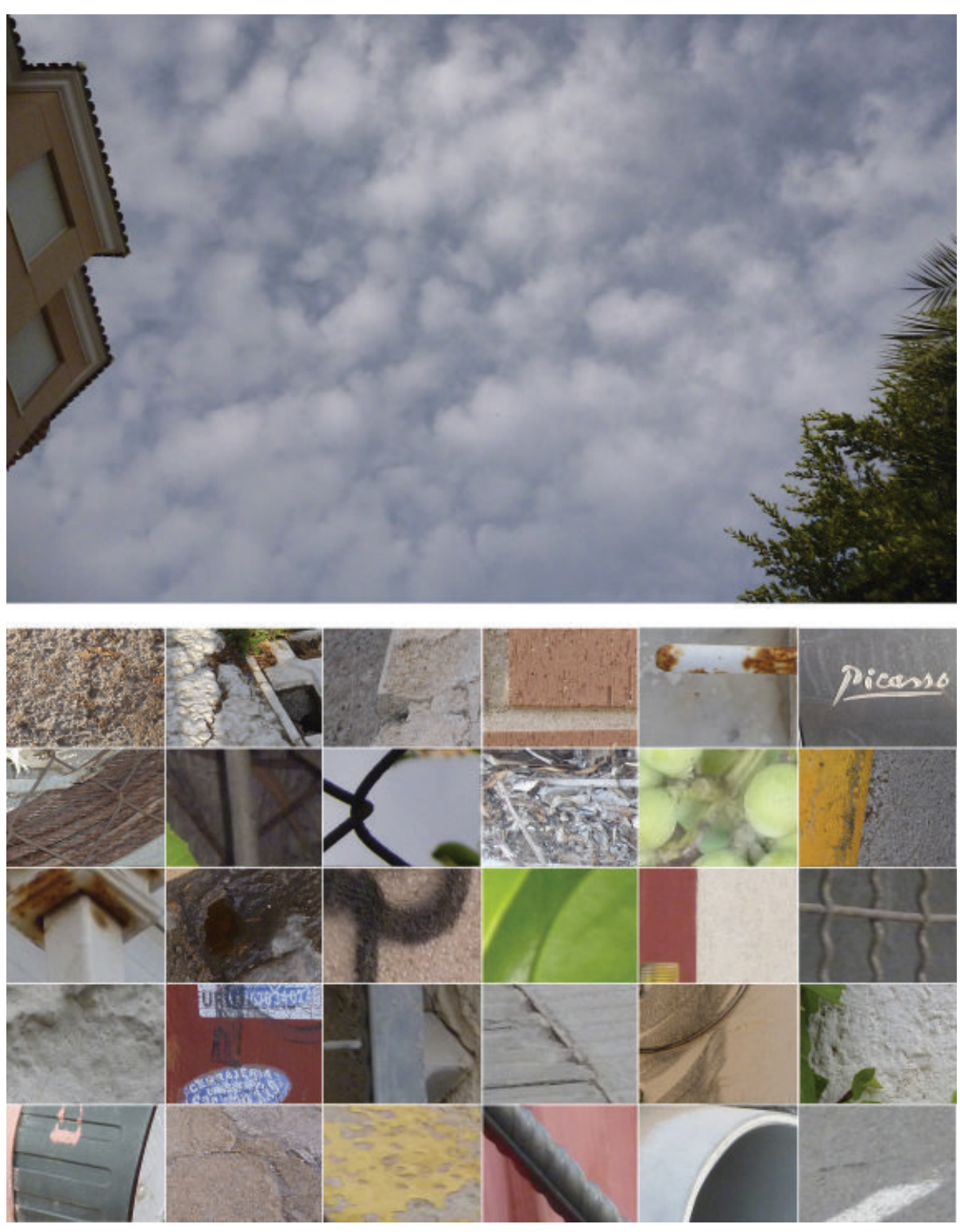
Looking down

Detengo el tiempo en el umbral de mi casa. Esta forma parte de una urbanización en un barrio periférico de la ciudad de Alicante. Si toda ella se volcá al mar; aquí - si cabe - el es aun mas protagonista.

En el Cabo de las huertas huele a mar. Tal vez ello ayude a obviar lo anodino de los cerramientos exteriores de esas colonias ausentes. Todas ellas se volcán hacia dentro e ignoran el espacio publico que las rodea. Y este las deprecia silenciosamente. No sabemos si lo primero es resultado de lo segundo o viceversa.

El vallado calla; pero callan también los elementos urbanos: aceras grises, encintados grises, calzadas grises, balcón grises.... Resaltan los pragmáticos registros de las inevitables instalaciones. El oxido se adueña de ellos ruborizándonos de rojo herrumbre. Incluso la pintura de la calzada se hiende en su abstracción.

Una solitaria colilla comulga con el asfalto retozándose en la desgana.. Una acometida de gas trepa por el cotegran y una señal de trafico( por supuesto de prohibición), se adhiere a los bloques de hormigón de ocasión...

Alguien quiso publicar su amor en este mismo lugar, entre la geometría de la frontera y la posibilidad de gritárselo.

\section{Looking up}

Seguramente olía a mar.... Ese olor que invita a levantar la mirada buscando su origen. Un rastreo que, afortunadamente aquí, se encuentra con el sol camino ya de otras latitudes que resaltar. O las copas de algunos árboles, tal vez desuña palmera, que te instala de nuevo en el lugar... aún con cierto horizonte.
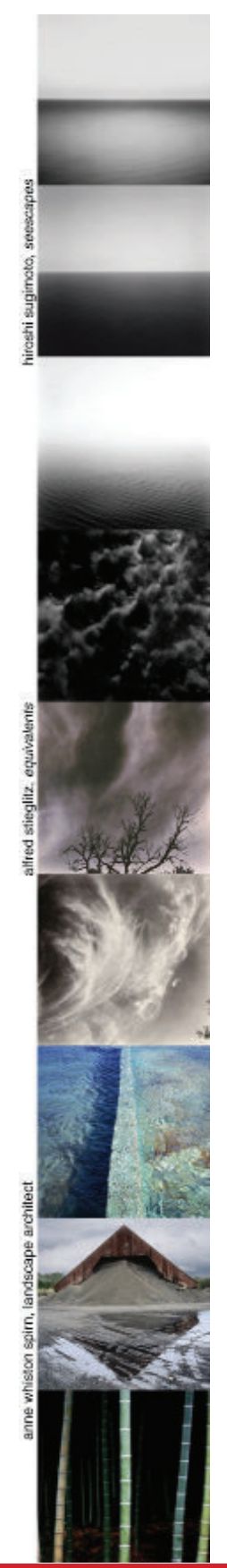

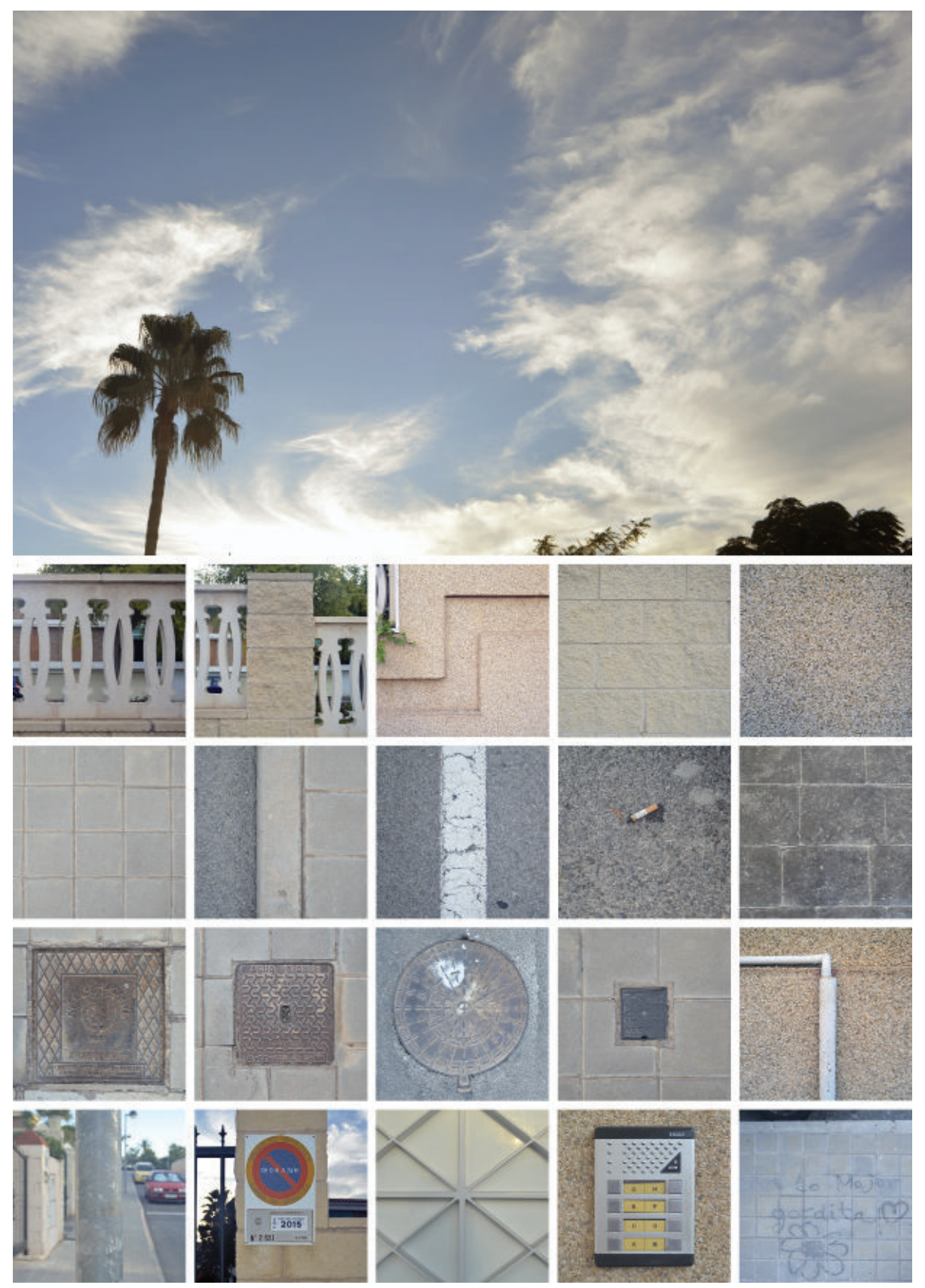

Alicante, Spain - 38 21'347.71'N 0²5’3.93”W 
El lugar fotografado se encuentra en un lugar de paso de camino a mi segunda vivienda en el camp d'Elx. Es un punto de recorrido cotidiano siendo la única forma de acceder a mi campo y de gran importancia debido a que en las noches de verano es un punto de reunión típico para mis vecinos y para mí. Todo lo fotografado va en base a los lugares en los que solemos colocarnos, a los que miramos, por donde pasamos... en defnitiva todo lo que participa de nuestra vida de forma directa y que nunca tenemos en cuenta.

\section{Looking up}

Cuando se echa una mirada hacia el cielo se puede ver un día prácticamente despejado donde, aunque las nubes se han hecho con gran parte del encuadre, se puede percibir perfectamente la estación en la que se ha realizado la foto.

El azul del cielo y el color de las plantas que aparecen, nos revela que la fotografía está realizada por la tarde.

Por otra parte, la presencia de los cables eléctricos nos revela que debe haber edifcios en las cercanías a los que les llegue la instalación. El cableado nos da información a su vez de la dirección en la que se encuentran estas viviendas y de cómo, al haber dos tipos distintos de instalación (con postes de madera, siendo estos anteriores, y de metal más actuales) es probable que haya un número considerable de casas.

Esto, además, puede ser confrmado al fjarse en la vegetación que aparece ya que esta está demasiado cuidada tratándose de árboles como ficus y pinos para la zona en la que se encuentra.

En el momento de la toma de fotografía no puede apreciarse, pero de fondo se escuchaba el sonido de un avión ya que el lugar está bajo una zona de tránsito aéreo.

\section{Looking down}

Cuando se echa la mirada hacia el suelo se observa un camino particular en el campo donde se aprecia las diferencias entre suelo de cultivo agrietado por las lluvias recientes y en el que se empiezan a ver ya los primeros brotes de patatas.

Además, se observa en dos puntos diferentes, pero uno junto al otro, el paso del agua a través de la red de aguas de riego en el que se puede apreciar que se ha regado recientemente al haber agua pero estar estancada y cómo, a causa del común paso del agua, han aparecido plantas dentro de la misma acequia.

Junto a esta, aparece parte del tronco de palmera vieja, posiblemente cortada a Junto a esta, aparece parte del tronco causa de alguna enfermedad como el picudo rojo.

En el borde del camino, y junto al asfalto, aparece vegetación plantada de forma artifcial que se ha hecho con los bordillos del campo de patatas y que, por un lado, está más cuidado que por otro debido a la proximidad del bancal (la parte seca) y a una vivienda privada (la parte más viva).

Hay una diferencia de material, no solo en el cambio de tierra-asfalto, sino también con las jardineras pegadas a las viviendas y tanto por la losa de hormigón en la entrada a una vivienda como el hormigón pintado de verde que hace las veces de acera.
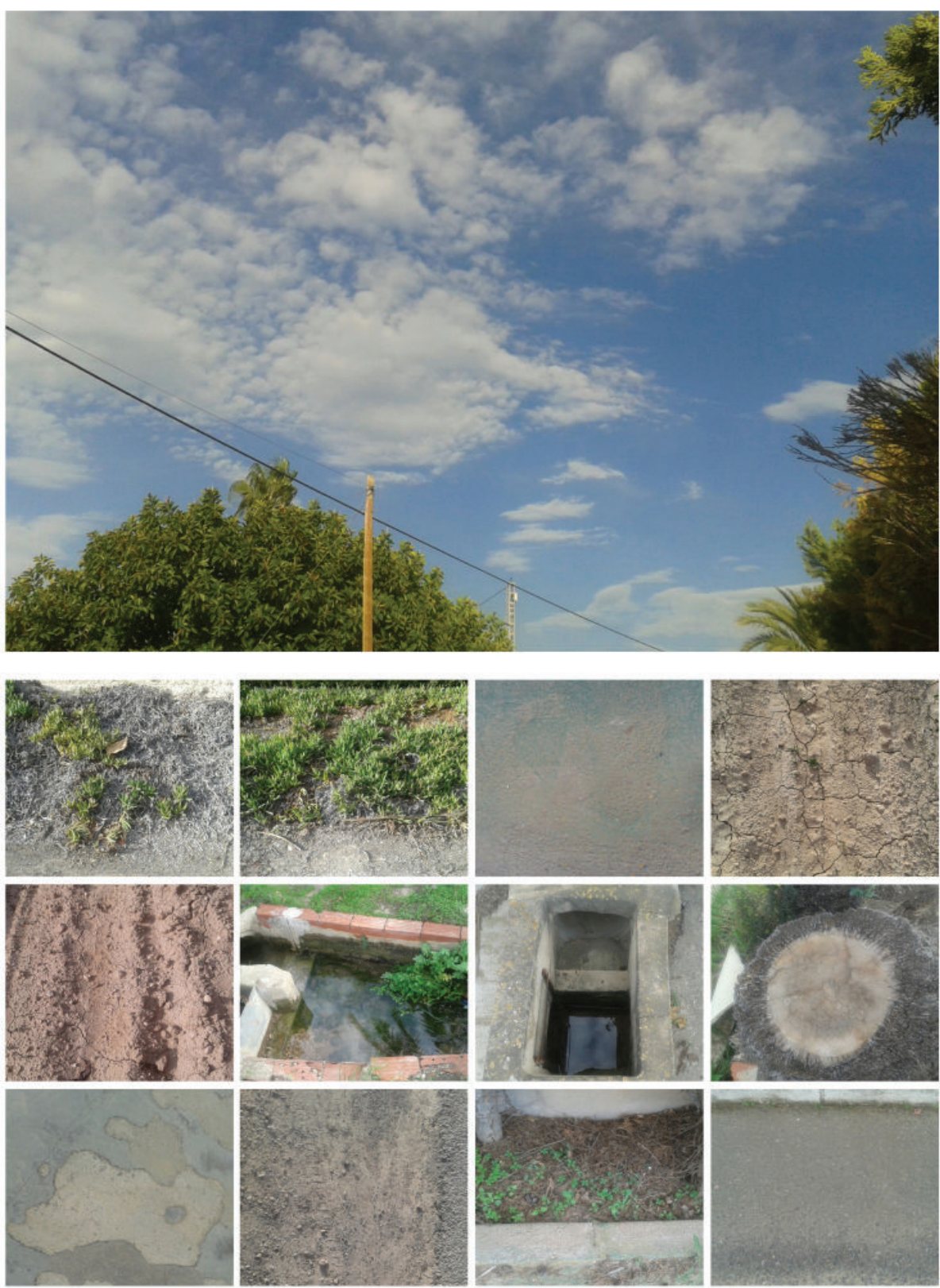
El lugar elegido para realizar las fotografías ha sido uno que forma parte de mi rutina diaria. Todos los días, para poder ir a la universidad cruzo una pequeña carretera para acceder al garaje, es este tramo el objeto del estudio.

Se encuentra en Alicante, en el barrio del Pla , es una pequeña vía de un solo carril, con aparcamiento en uno de los lados y dos aceras peatonales.

En primer lugar, mirando hacia arriba observamos un pedacito de cielo, encajonado por los edificio colindantes, como ya he comentado, la calle es estrecha, así que la perspectiva no nos permite ver gran cosa, a penas unas pocas nubes y los picos de los edificio por las esquinas, a modo de marco.

En segundo lugar, y a mi parecer, la parte mas importante de este ejercicio se encuentra cuando miramos hacia abajo, que es cuando nos cuenta de la trascendencia. En cuanto a esta visión, yo destacaría que podemos encontrar dos grandes grupos: el de cosas fijas o permanentes (los ladrillos, las marcas viales, el mobiliario...) y el de cosas efímeras (un envoltorio, hojas, flores, charcos...). Lo cierto es que pese a ser un lugar cotidiano para mi desde hace más de 15 años, era la primera vez que me ponía a mirarlo con detalle, lo cual me ha permitido descubrir cosas que ignoraba, como las irregularidades del pavimento, la transición de unas baldosas a otras, gotas de pintura sobre el bordillo o la manera en la que las sombras inciden en el suelo.

He decidido llamar a esta sería de fotografía "look it now" porque es lo que pensé mientras las tomaba, mejor mirarlo ahora, porque quien sabe si mañana seguirá todo igual, si algo habrá cambiado o desaparecido. Lo más probable es que si mañana volvemos al mismo lugar muchas de las cosas las encontraremos de la misma manera pero hay otras que no, otras habrán desaparecido y por el contrario también podremos encontrar unas nuevas que no estaban con anterioridad.

Me ha parecido un ejercicio muy interesante ya que te hace ver más a ya de lo que ves es tu día a día y te ayuda a descubrir cosas nuevas de un entorno que creías ya conocido y familiar y te abre a una nueva manera de ver, vivir los lugares y de interactuar con ellos.
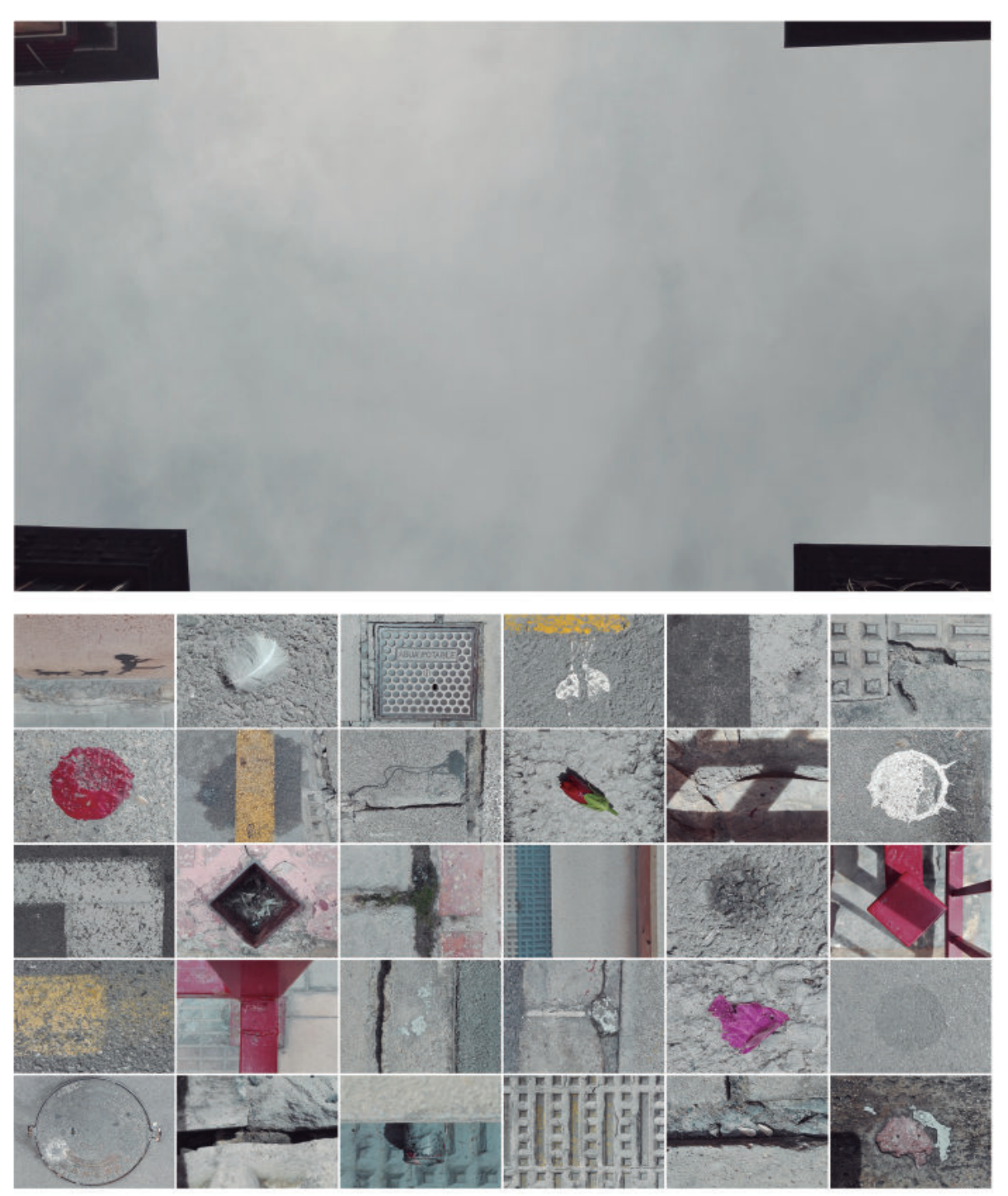
El trabajo se basa en la calle dónde se ubica mi casa. He escogido esta ubicación ya que es uno de los lugares que más frecuento.

Las imágenes reflejan pequeños detalles que caracterizan este lugar, todas ellas tienen una historia tras de sí. Dichas imágenes rondan todos los ámbitos, desde las persianas que caracterizan esta región, como fachadas, carteles, la sombra de un perro o hasta grietas y toma tierras... cada una forma parte de una vivencia o suceso que describe este lugar, por ejemplo si no existiese el local del pintor no habría en la fachada cuadrados de pruebas de pinturas o si no fuese por que hay una falla activa no habrían tantas grietas.

En definitiva, todas las imágenes desvelan un hecho que no había percibido y otro que solo en unas pocas se puede intuir, y son el nombre de este trabajo.
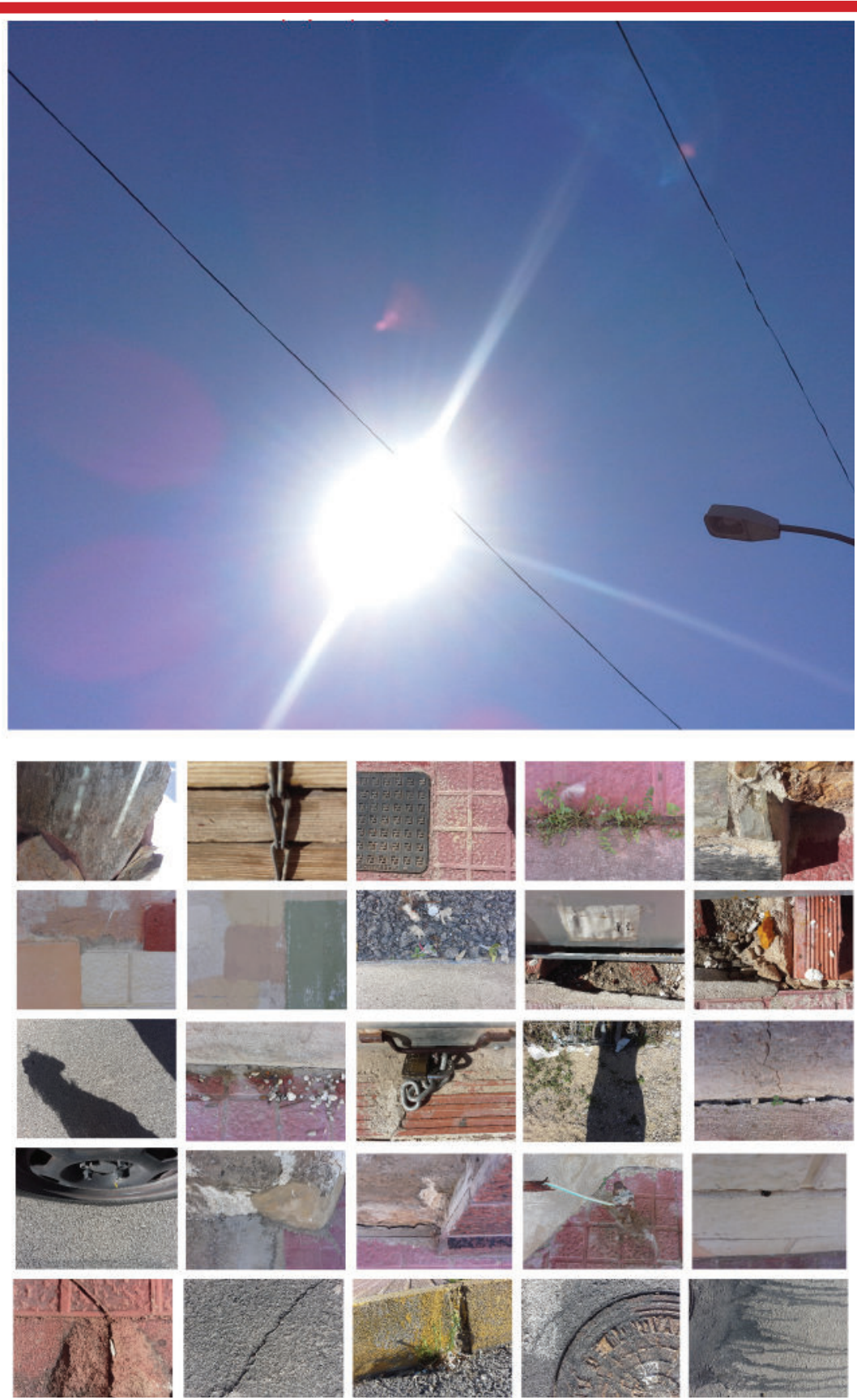

Monovar, Spain - 3843'859.8”N 083'12.26”W 
Mi ventana está en el municipio de Crevillent, específicamente en el ático de la calle Blasco Ibáñez No 12 con la siguiente cordenadas 38.248322, -0.809945 . Crevillent es una pequeña ciudad en el Baix Vinapoló con una población de alrededor de 28.000. Mi ventana se encuentra en un edificio situado en el centro de Crevillent. Debido a la altura del edificio, que pasa a ser uno de los más altos del pueblo, puedo ver ningún problema nigun, los otros edificios que están a su alrededor, así como las montañas en el municipio.

Ventana hacia el interior podemos encontrar mi habitación. Esto está por encima de la mesa donde paso la mayor parte del tiempo estoy trabajando en casa y estudiar. Realmente he pasado tiempo buscando poe su tamnien, observando cada calle o parque veo desde aquí.

Al hacer fotografías, me di cuenta de la cantidad de detalles que llaman la atención. Totas las imágenes extraídas son parte de mi curiosidad, que lo que mi vista se establece cada vez que miro por la ventana.

Es curioso cómo la perspectiva cambia si miramos de arriba a abajo de modo. Las cosas que no me establecidos no mirarlos desde otra perspectiva. En algunas de las fotografías que he hecho varias escuelas, una gran cantidad de edificios, tanto antiguos como recientes observadas más. Tambien con más detalle, unos voladizos curiosos, con sombrillas y bastones.
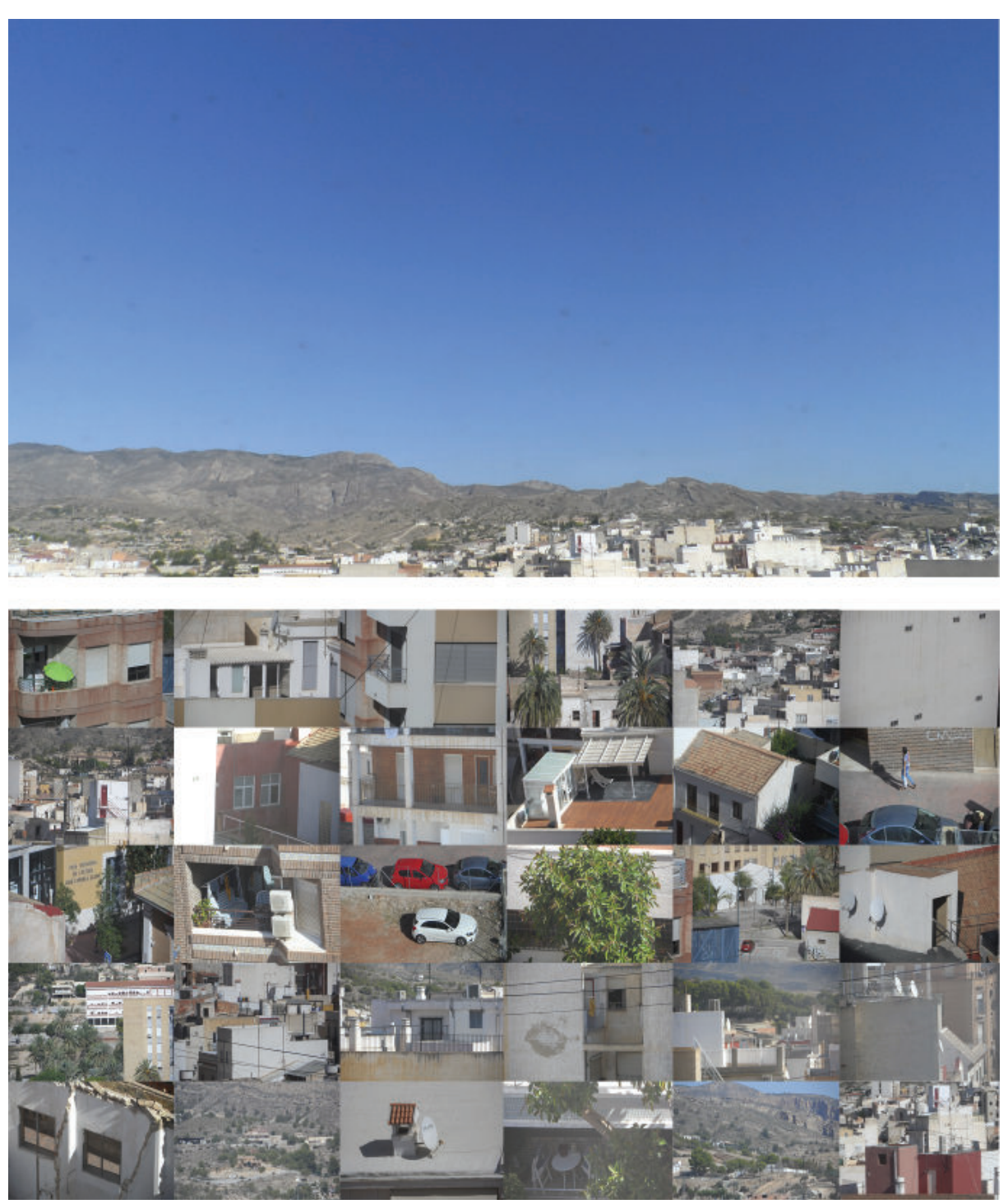
El emplazamiento elegido para la realización de las fotografías se sitúa en mi segunda residencia, una casa de campo en una vereda en la carretera que une Monovar y Novelda.

En la parcela de la casa de campo hay un bancal. Es desde allí desde donde se han tomado las instantáneas.

La que se sitúa por encima de la línea del horizonte muestra el cielo despejado, propio del verano, junto a las ramas más altas de dos árboles: una higuera y un pino. Estos para mí son dos elementos muy significativos del lugar por varios motivos. Lo primero, porque son los dos árboles que se ven desde la ventana de mi cuarto, por lo que los veo diariamente durante los días en los que vivo allí. Lo segundo, porque son los únicos ejemplares de estas especies que hay en toda la parcela, y son dos ejemplares muy grandes y vivos.

Las fotografías por debajo de la línea del horizonte se sitúan en torno al terreno del bancal. Este es un lugar que visito a menudo porque suele haber frutas y verduras creciendo, y siempre es curioso contemplar su evolución. Ahora, como el verano ha pasado, se aprecia un cambio importante: la mayoría de frutas y verduras han desaparecido y las plantas han muerto o tienen otro aspecto.

He centrado el foco de mi cámara principalmente en esta vida vegetal en constante cambio. Encontramos por una parte pequeñas malas hierbas que crecen entre las piedras; rastrojos secos, restos de las que murieron; tubos de riego; y los árboles que invaden todo el campo: olivos y almendros. Después mi atención se fija en los ladrillos que se apilan colindantes a la casa, escombros de obras pasadas; y la puerta a un cobertizo donde se guardan algunas herramientas. Los límites de la parcela se definen por una verja metálica.

Conforme fotografío otros elementos aislados cogen relieve: una oliva solitaria, unas flores de color intenso, o unas hojas verdes de alguna especie que desconozco. Y la presencia perpetua de la tierra y las piedras blancas a lo largo de todo el terreno.

El paisaje es campestre, $y$ tanto si miro hacia arriba como si miro hacia abajo se pone en relieve. Presto atención sobre todo a la vegetación, que es lo que más me gusta del lugar, pero también la fijo en aquellas cosas que son de creación humana y chocan o se integran en él.
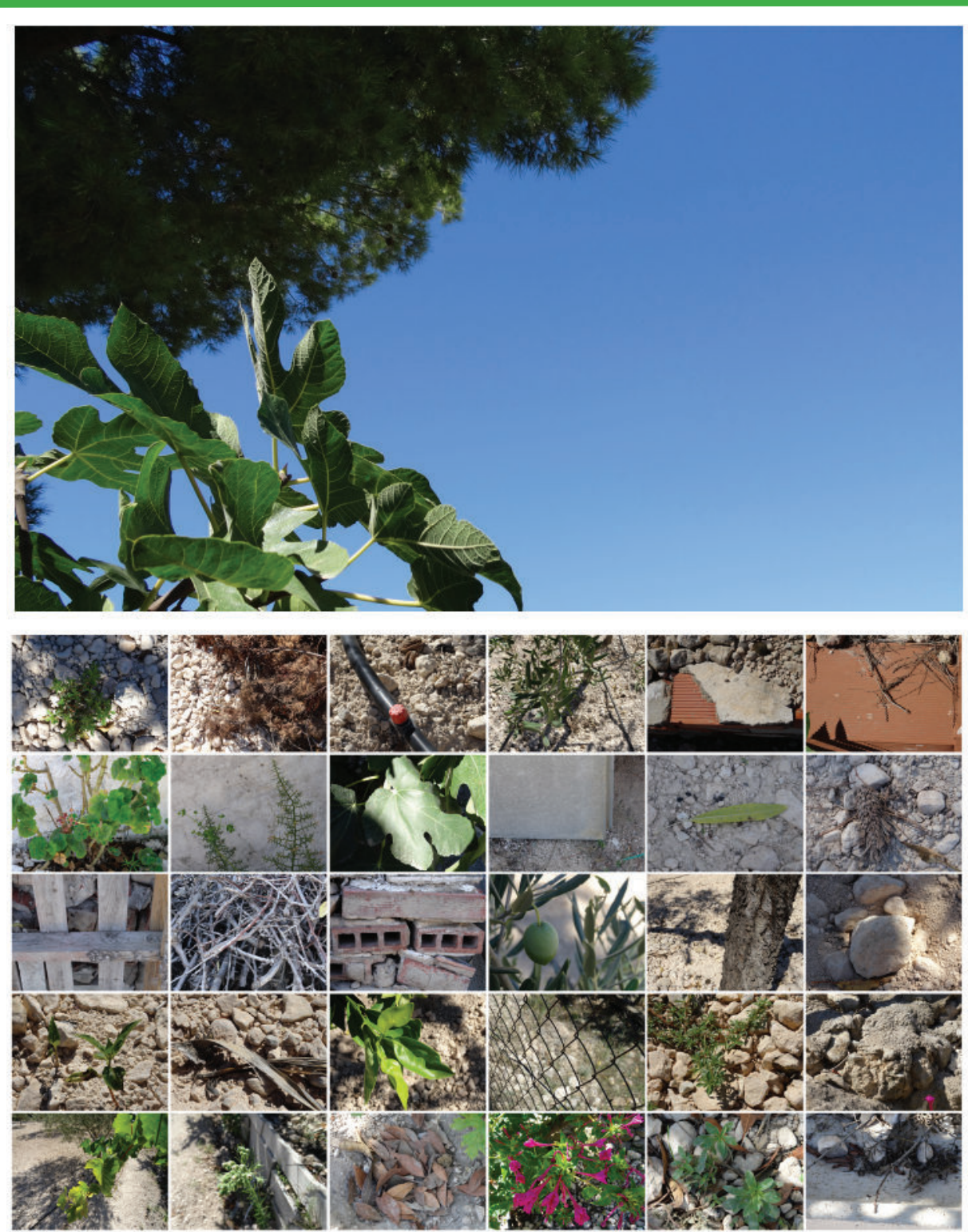